\title{
STRATEGIC HUMAN RESOURCE MANAGEMENT (SHRM) DI KEMENPAN-RB REPUBLIK INDONESIA
}

\author{
Nike Mutiara Fauziah ${ }^{1}$, Andri Wahyu Prasetyo ${ }^{2}$ \\ nikemutiarafa@untidar.ac.id ${ }^{1}$, andrie_prasetyo10@yahoo.com ${ }^{2}$ \\ ${ }^{1}$ Jurusan Ilmu Administrasi Negara, Universitas Tidar, Magelang \\ ${ }^{2}$ Analis Kepegawaian, Balai Litbang Kesehatan Kelas 1, Kementerian Kesehatan Republik \\ Indonesia, Banjarnegara
}

\begin{abstract}
This study focuses on change management towards Strategic Human Resource Management (SHRM) in the Ministry of Administrative and Bureaucratic Reform of the Republic of Indonesia (KemenPAN$R B)$. Considering on idea of change HR management towards SHRM which could not be implemented, and various issues related to human resource management in KemenPAN-RB. This study uses a qualitative method with postpositivis approach. The object of this research is the Ministry of Administrative and Bureaucratic Reform of The Republic of Indonesia as a unit of analysis. The data analysis technique in this research was conducted by triangulation of source. The results show the human resource management in KemenPAN-RB still Partial Human Resource Management in managing human resources, because of human resource management are still not integrated which causes various problems in aspects of competency management, recruitment and selection, human resource development, performance appraisal, career management and total reward system. The idea of change towards SHRM could not be implemented due to various influence factors. There are some factors influenced implementing of SHRM according to the result of author analysis taken from various interviews has been conducted those are Mindset factor, Organizational, Leadership, Sharing Knowledge, Infrastructure and HR Competency.
\end{abstract}

Key Words: Strategic Human Resource Management; Change Management; Bureaucratic Reform.

\section{Pendahuluan}

Indonesia sebagai negara terbesar di Asia Tenggara masih tertinggal jauh dibandingkan dengan negara lainnya di Asia Tenggara dalam hal pengelolaan pemerintah yang efektif dan efisien. Data The Most World's Efficient Governments 2019, Indonesia menempati peringkat ke-50. Berbagai upaya perbaikan terus dilakukan pemerintahan Indonesia, upaya perbaikan tersebut tidak terlepas dari pegawai negeri sebagai salah satu Agent of Change dalam mendukung pembangunan suatu negara. Salah satu langkah reformasi dalam bidang SDM pegawai negeri yaitu dengan dibuatnya Undang-Undang Nomor 5 Tahun 2014 tentang Aparatur Sipil Negara (UU ASN). UU ASN ini lebih menekankan pada Sistem Merit dalam pengelolaan SDM pegawai negeri.

Terdapat beberapa Kementerian dan Lembaga Pemerintah yang bertanggungjawab dalam mengelola ASN di Indonesia. Salah satu lembaga formulator kebijakan dalam manajemen ASN di Indonesia adalah Kementerian Pendayagunaan Aparatur Negara dan Reformasi Birokrasi (KemenPAN-RB). KemenPAN-RB memiliki kebijakan reformasi birokrasi sebagai agenda nasional jangka panjang yang ditindaklanjuti dengan Peraturan Menteri Pendayagunaan Aparatur Negara dan Reformasi Birokrasi Nomor 11 Tahun 2015 tentang Roadmap Reformasi Birokrasi yang diturunkan dalam 8 Program Area Perubahan dan Sasaran Reformasi Birokrasi. Salah satu dari 8 Program Area Perubahan dan Sasaran Reformasi Birokrasi tersebut adalah Area Perubahan Sumber Daya Manusia Aparatur Sipil Negara (Roadmap Reformasi Birokrasi, 2015).

Dari 8 area perubahan, Area Perubahan SDM Aparatur terdapat sasaran yang realisasinya belum sesuai target dalam 
terkait dengan pengembangan kompetensi minimal. Dalam draft RPP Manajemen PNS diatur bahwa setiap pegawai dalam 1 tahun minimal 80 jam pelajaran atau setara dengan 12 hari kerja untuk mengembangkan kompetensinya sementara realisasinya hanya $16,53 \%$ dari target $20 \%$ sehingga belum mencapai target padahal kompetensi merupakan salah satu indikator dalam menentukan kualitas SDM.

Sebagai kementerian yang memilki wewenang dalam perumusan dan penetapan kebijakan manajemen ASN, sebelum menjalankan fungsi eksternal lembaganya, KemenPAN-RB seharusnya mampu untuk mereformasi internalnya terlebih dahulu. Salah satu bentuk reformasi internal dalam manajemen ASN di internal KemenPAN-RB adalah digagasnya perubahan sistem manajemen SDM KemenPAN-RB ke arah Strategic Human Resource Management (SHRM) dari manajemen SDM yang parsial dan menggunakan Aplikasi Sistem Informasi Kepegawaian (ASIK) yang hanya menyediakan data personal dan tidak berpengaruh terhadap aspek manajemen SDM lainnya menjadi Integrated Human Resource Management System (IHRMS).

KemenPAN-RB masih terus berupaya melakukan maping sumber daya sehingga belum mengimplementasikan IHRMS dengan maksimal karena Sumber daya pegawai untuk mengoperasikan sistem ini masih belum mumpuni sehingga masih membutuhkan bantuan pihak ke-3. Perubahan Struktur Organisasi dan Tata Kerja (SOTK) di lingkungan KemenPAN-RB pula menyebabkan perubahan standarisasi kompetensi, indikator kinerja utama, nomenklatur struktur organisasi, penyelarasan database, dan penilaian ulang kemampuan organisasi sehingga untuk mengimplementasikan IHRMS masih memerlukan penyempurnaan yang disesuaikan dengan SOTK.

Hal ini terbukti dari hasil laporan Audit MSDM bahwa manajemen SDM di lingkungan KemenPAN-RB memiliki masalah dari setiap dimensi. Skor rata-rata untuk semua dimensi terletak antara 2,61, ini menunjukkan bahwa pada semua dimensi terindikasi adanya masalah. Peringkat indikasi permasalahan yang tertinggi, yakni pada dimensi Penghargaan yaitu 3,07 .
Rumusan masalah yang dapat diambil dari uraian latar belakang di atas diantaranya:

1. Bagaimana Manajemen Perubahan dalam Manajemen SDM di KemenPAN-RB dilakukan?

2. Aspek-aspek apa yang mmendorong pendekatan SHRM di KemenPAN$\mathrm{RB}$ ?

3. Bagaimana model implementasi SHRM yang tepat di KemenPAN-RB?

Berdasarkan pada latarbelakang dan rumusan masalah, maka tujuan yang hendak dicapai oleh penulis dalam melakukan penelitian ini adalah sebagai berikut diantaranya: Untuk menganalisis apakah Perubahan dalam Manajemen SDM di KemenPAN-RB ini sejalan dengan konsep Strategic Human Resource Management (SHRM) dalam mengelola SDMnya. Kemudian yang kedua yaitu untuk mengetahui faktor-faktor apa yang dalam Strategic Human Resource Management (SHRM) di KemenPAN-RB dan terakhir adalah membuat model implementasi SHRM di KemenPANRB.

\section{Tinjauan Pustaka}

\section{A. Manajemen Perubahan}

Perubahan dapat terjadi secara evolusioner maupun revolusioner. Tidak semua perubahan yang terjadi akan menimbukkan kondisi yang lebih baik, hingga dalam hal demikian tentu perlu diupayakan agar bila dimungkinkan perubahan diarahkan ke arah hal yang lebih baik dibandingkan kondisi sebelumnya. Transisi dari kondisi awal hingga kondisi kemudian memerlukan proses transformasi yang tidak selalu berlangsung dengan lancarnya, mengingat bahwa perubahan-perubahan sering kali disertai dengan aneka macam konflik yang muncul. Salah satu sasaran manajemen perubahan adalah mengupayakan agar proses transformasi tersebut berlangsung dalam waktu yang relatif cepat dengan kesulitankesulitan seminimal mungkin hal ini dijelaskan lebih lanjut dalam Organizational Change.

Menurut konsultan Manajemen, Manchester Open Learning (MOL) dalam laporannya Planning and Managing Change proses perubahan itu digambarkan dalam beberapa proses. Proses pertama yaitu Recognize the Problem or Opportunity dengan 
memetakan permasalahan dalam situasi bekerja yang membuat kita sadar akan kebutuhan untuk berubah selain itu perubahan juga dapat terjadi karena adanya kesempatan. Proses kedua yaitu Identify the Required Change dengan menganalisis situasi lebih rinci, dengan menyusun beberapa alternatif solusi dan menggagas apa perubahan yang akan dibuat. Proses berikutnya yaitu Implement Solution baik melalui merubah perilaku pegawai, sosialiasi dan aturan administrasi, dan proses terakhir yaitu Evaluation, ini adalah proses yang paling penting untuk terus mengawasi perubahan secara lebih dekat agar dapat memastikan hasil dan manfaat yang didapat dari adanya perubahan (MOL, 1993, p.8-10).

Kurt Lewin juga menjelaskan bahwa terdapat suatu fase yang berkaitan dengan perubahan yang direncanakan (Lewin, 1951, p.123-124). Kurt Lewin menjelaskan bahwa setiap upaya perubahan dapat dipandang sebagai sebuah proses yang terdiri dari tiga macam fase, sebagai berikut:

\section{Tabel 1. Proses Manajemen Perubahan}

\begin{tabular}{|c|c|c|}
\hline $\begin{array}{l}\text { Fase 1: } \\
\text { Unfreezing }\end{array}$ & $\begin{array}{l}\text { Fase II : } \\
\text { Changing }\end{array}$ & $\begin{array}{l}\text { Fase III : } \\
\text { Refreezing }\end{array}$ \\
\hline $\begin{array}{l}\text { Menciptakan } \\
\text { kebutuhan } \\
\text { akan } \\
\text { perubahan } \\
\text { Meminimasi } \\
\text { tantangan } \\
\text { terhadap } \\
\text { Perubahan }\end{array}$ & $\begin{array}{l}\text { Mengubah } \\
\text { orang- } \\
\text { orang } \\
\text { (individu- } \\
\text { individu) } \\
\text { dan } \\
\text { kelompok- } \\
\text { kelompok: } \\
\text { tugas-tugas } \\
\text { struktur, } \\
\text { dan } \\
\text { teknologi }\end{array}$ & $\begin{array}{l}\text { Memperkuat } \\
\text { hasil-hasil } \\
\text { Mengevaluasi } \\
\text { hasil-hasil } \\
\text { Membuat } \\
\text { modifikasi- } \\
\text { modifikasi } \\
\text { konstruktif }\end{array}$ \\
\hline
\end{tabular}

Sumber: Lewin, 1951.

"Successful Organizations cannot remain static if they hope to continue that success, they must change in order to keep up with a changing world" (Spector, 2001, p.3). Bahwa kesuksesan tidak tergantung pada kondisinya yang stabil tetapi organisasi yang sukses berkesinambungan tergantung pada upayanya untuk melakukan perubahan. Hal ini didukung oleh Robbins bahwa makin banyak organisasi dewasa ini menghadapi lingkungan yang dinamis, dan yang mengalami perubahan dan yang menyebabkan timbulnya keharusan untuk berubah, terdapat enam macam kekuatan yang bekerja simultan bagi perubahan, diantaranya: Sifat angkatan kerja, teknologi, kondisi ekonomi, tren sosial, politik dunia, dan sifat persaingan yang berubah. Secara singkat Robbins menyatakan "change is making things different".

\section{B. Strategic Human Resource Management (SHRM)}

Strategic Human Resource Management (SHRM) dipahami sebagai bertambahnya nilai terhadap efektifitas organisasi dengan mengintegrasikan people, strategy, values, and performance (Becker et al, 2001; dalam Caldwell, Truong, Linh, Tuan; 2015., p.75). Dengan menghubungkan strategi organisasi secara keseluruhan dengan sistem Manajemen SDM menjadi sesuatu yang penting dalam memaksimalkan kinerja organisasi dengan meningkatkan inisiatif, kreativitas dan komitmen pegawai untuk sukses (Covey, 2004; Senge, 2006; dalam Caldwell, Truong, Linh, Tuan; 2015, p.86). Kesuksesan SHRM tergantung pada kemampuan organisasi untuk secara mendalam mendesain dan implementasi secara konsisten seperangkat kebijakan dan praktek kerja internal yang memastikan bahwa pengetahuan kolektif pegawai, keterampilan, dan kemampuannya dapat berkontribusi dalam mencapai tujuan organisasi (Huselid et al., 1997, p.172). Berikut digambarkan bagaimana model implementasi SHRM: 


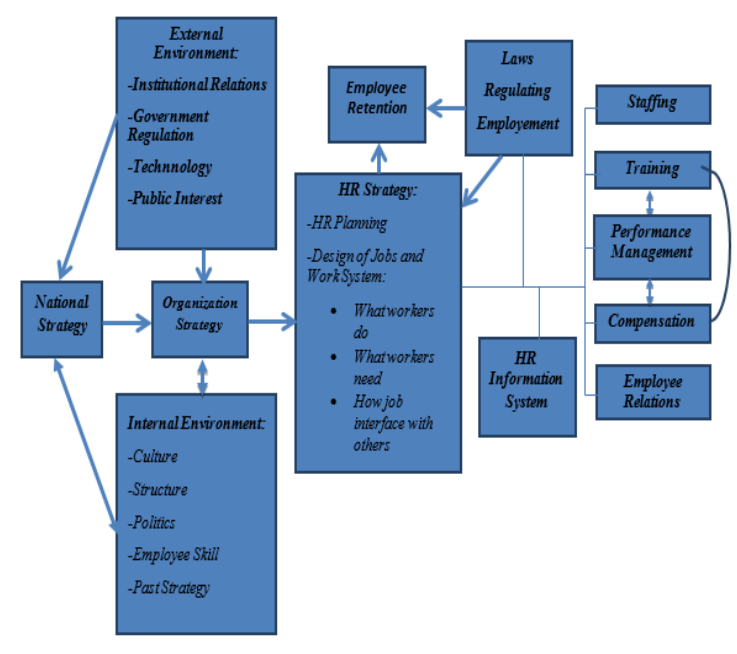

Gambar 1. A Model of Strategic Human Resource Management

Sumber: Mello, 2015

Manajemen sumber daya manusia strategis (SHRM) membahas seputar sistem sumber daya manusia yang disesuaikan dengan tuntutan strategi organisasi untuk manajemen sumber daya manusia direncanakan. Kegiatan dimaksudkan untuk memungkinkan organisasi dalam mencapai tujuan. Manajemen sumber daya manusia strategis (SHRM) adalah sebuah konsep yang mengintegrasikan kegiatan manajemen sumber daya manusia tradisional dengan perencanaan dan pelaksanaan strategis secara keseluruhan. SHRM mengintegrasikan pertimbangan sumber daya manusia dengan aspek lainnya seperti keuangan, dan teknologi sumber daya dalam pengaturan tujuan dan memecahkan masalah organisasi yangkompleks. SHRM juga menekankan pelaksanaan serangkaian kebijakan dan praktik yang akan membangun talent pool yang berisi keterampilan, pengetahuan, dan kemampuan yang relevan dengan tujuan organisasi. Dengan demikian berbagai solusi untuk memecahkan masalah organisasi dalam mencapai tujuan organisasi akan meningkat. (Mello, 2016).

Menurut Abu T.R.Rahman bahwa terjadi perubahan manajemen yang mirip antara kedua organisasi baik sektor publik maupun sektor swasta yang dibeberapa sektor memiliki sistem operasi yang sama contohnya kesehatan, pendidikan, transportasi, dll. Andreescu (2004) and Manning (2010) dalam Aruan (2016) mengindikasi bahwa masih terbatasnya studi terkait SHRM di sektor publik. Hal ini mungkin disebahkan oleh kondisi (natures of business) yang berbeda antara sektor swasta dan sektor publik. Namun, Llewellyn dan Tappin (2003) berpendapat kepegawaian negari masih menghadapi masalah yang mirip dengan sektor swasta. Sebagaimana Manning (2010), strategi dalam mengelola kepegawaian negari dilakukan dalam menanggapi berbagai persaingan yang berasal bukan dari pasar tapi dari struktur politik yang kompleks, ekonomi, hukum dan organisasi, proses, dan hubungan antar lembaga.Walaupun memiliki karakteristik yang berbeda antara sektor swasta dan sektor publik, Tompkins (2002) berpendapat bahwa konsep SHRM juga dapat menjanjikan bagi sektor publik untuk meningkatkan kinerja pemerintahan.

\section{Faktor-faktor yang Mempengaruhi dalam Strategic Human Resource Management}

Untuk menerapkan SHRM sebagai pendekatan yang mengintegrasikan tujuan strategis organisasi, tujuan strategis SDM dan manajemen SDM itu sendiri tentu bukanlah hal yang mudah. Ketika kita bertanya seberapa baik organisasi dapat menangani rencana suksesi sebagai bagian dari SHRM untuk level eksekutif pimpinan, $66 \%$ menjawab sangat buruk (Pynes, 2009). Berdasarkan beberapa contoh, beberapa organisasi pemerintahan mengerti tentang kebutuhan adanya rencana SHRM, tetapi kebanyak dari organisasi pemerintahan tersebut tidak memiliki waktu, sumber daya dan dukungan untuk mengimplementasikan hal ini. The Government Accountability Office mengidentifikasi faktor-faktor yang mempengaruhi dalam SHRM seringkali gagal:

1. Lack of on - going support and interest from leadership

2. Succession planning is not seen as a priority

3. Funding is not sufficient

4. Recruitment and retention, particularly in critical management areas,

5. is perceived to be sufficient to meet organizational needs

6. Resistance from middle managers who already feel overburdened with 
other "initiatives" not central to their job responsibilities

7. Employee suspicion toward unsure program goals, poor communication and organization is too small to sustain a full - scale program (Flynn, 2006, p. 6).

Penyebab lainnya mengapa SHRM diabaikan dalam organisasi pemerintahan adalah karena kurangnya pegawai yang profesional yang bertanggungjawab dalam SDM sehingga organisasi pemerintah kekurangan kemampuan dan keterampilan yang diperlukan untuk lebih proaktif dalam HRM. Selain itu SDM belum menjadi mitra strategis organisasi, karena untuk menjadi mitra strategis organisasi departemen SDM harus memiliki profesionalitas dan pemahaman proses bisnis internal yang tinggi.

\section{Kerangka Konseptual Penelitian}

Berdasarkan tujuan penelitian ini penulis ingin mengetahui apakah Perubahan dalam Manajemen SDM di KemenPAN-RB ini menganut teori Strategic Human Resource Management (SHRM) atau Parsial Human Resource Managementdalam mengelola SDMnya, Faktor-faktor apa yang mempengaruhi dalam Perubahan Manajemen SDM dengan Strategic Human Resource Management (SHRM) di KemenPAN-RB dan bagaimana model implementasi yang tepat sesuai dengan kondisi sebenarnya yang dibutuhkan apabila ingin menerapkan SHRM di KemenPAN-RBdengan menggunakan kerangka teoretis yang telah dijelaskan sebelumnya. Kerangka pemikiran dalam penelitian ini dapat digambarkan dalam bagan berikut:

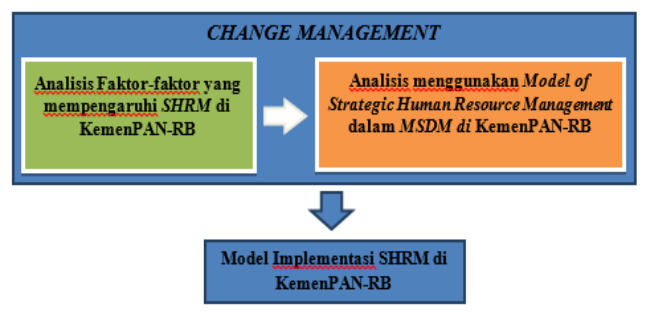

Gambar 2 Kerangka Pemikiran

Sumber: Sintesis Penulis, 2019
Penelitian ini menggunakan paradigma penelitian postpositivis. Metode penelitian yang digunakan dalam penelitian ini adalah metode penelitian kualitatif. Obyek penelitian dalam karya tulis ilmiah ini adalah Kementerian Pendayagunaan Aparatur Negara dan Reformasi Birokrasi (KemenPAN-RB) Republik Indonesia sebagai unit analisis. Hal ini juga berlaku pada informan penelitian yang dijadikan sebagai narasumber. Teknik pengumpulan data yang dilakukan dalam penelitian ini adalah Studi Kepustakaan (library study) dan Studi lapangan (field study). Dalam penelitian ini data mengacu pada esensi manusia, obyek dan situasi, sehingga data yang diperoleh selama di lapanganan akan diperiksa, dipilih, digolongkan, dievaluasi, diperbandingkan, disintesiskan dan dilakukan perenungan data yang dikodekan serta mengkaji data mentah dan data yang direkam. Adapun teknik analisis data yang dalam penelitian ini dilakukan dengan triangulasi sumber.

\section{Hasil Penelitian dan Pembahasan}

Penelitian berdasarkan hasil analisis lapangan melalui observasi, wawancara, dan studi dokumen yang menggambarkan fokus penelitian yaitu Manajemen Perubahan dalam Strategic Human Resource Management (SHRM) di Kementerian Pendayagunaan Aparatur Negara dan Reformasi Birokrasi (KemenPAN-RB) Republik Indonesia.

\section{A. Manajemen Perubahan dalam Manajemen Sumber Daya Manusia KemenPAN-RB}

Kebutuhan untuk perubahan yang dilakukan oleh KemenPAN-RB dalam rangka menciptakan good governance melalui reformasi birokrasi. Refomasi birokrasi adalah sebuah perubahan besar dalam paradigma dan tata kelola pemerintahan, yang mengarah pada organisasi (kelembagaan), tatalaksana, SDM, pelayanan, akuntabilitas dan perundangundangan serta pola pikir (Grand Desain Reformasi Birokrasi Indonesia 2010- 2025, 2010, p.2, yang selanjutnya disingkat GDRB). Berdasarkan hasil temuan lapangan diperoleh bahwa KemenPAN-RB memiliki unit yang bertanggungjawab dalam reformasi birokrasi internal KemenPAN-RB, unit ini yang

\section{Metode Penelitian}


mendorong percepatan reformasi birokrasi internal KemenPAN-RB

Selain adanya Bagian Organisasi dan Reformasi Birokrasi Internal yang bertanggungjawab dalam akselerasi reformasi birokrasi di KemenPAN-RB, hal lain menunjukan bahwa KemenPAN-RB merupakan organisasi sektor publik yang terbuka terhadap perubahan berdasarkan hasil wawancara dengan Sekretaris Kementerian PAN-RB (9 Januari 2019), bahwa sesuai dengan peran Kementerian PAN-RB dalam pelaksanaan reformasi birokrasi, menurutnya organisasi Kementerian PAN-RB dan SDM di dalamnya harus menjadi ujung tombak dan teladan pelaksanaan reformasi birokrasi bagi $\mathrm{K} / \mathrm{L} / \mathrm{Pemda}$, untuk itu KemenPAN-RB harus dapat menginisiasi perubahan dan keterbukaan harus menjadi bagian dari proses kerja Kementerian PAN-RB dalam melakukan penataan birokrasi baik secara nasional maupun institusional. Keterbukaan yang dimaksud disini adalah KemenPAN-RB terbuka terhadap berbagai perubahan kondisi lingkungan strategis, terbuka terhadap masukan dan pandangan yang konstruktif dari seluruh stakeholder yang ada, misalnya masukan dan saran dalam pelaksanaan berbagai kebijakan KemenPAN-RB, serta mengenai pelaksanaan praktik terbaik dalam berbagai aspek reformasi birokrasi.

Berbagai upaya perubahan ke arah perbaikan yang dilakukan dalam implementasinya tidaklah mudah karena disebabkan salah satunya oleh perbedaan budaya antar generasi, seperti yang diungkapkan oleh Kepala Bagian Sumber Daya Manusia Kementerian Pendayagunaan Aparatur Negara dan Reformasi Birokrasi Republik Indonesia (5 November 2019). Menurut hasil wawancara dengan Sekretaris KemenPAN-RB (9 Januari 2019) adapun upaya yang dilakukan untuk membantu mewujudkan reformasi birokrasi di internal KemenPAN-RB dengan cara mengefisiensi dan mengeefektifkan proses bisnis di KemenPAN-RB melalui penggunaan IT, oleh karena itu di KemenPAN-RB terdapat berbagai aplikasi yang diperuntukkan untuk berbagai kepentingan baik untuk urusan internal maupun eksternal, dengan tujuan agar pelaksanaan pemerintahan dapat berjalan dengan efektif, efisien, transparan, akuntabel, dan dapat diakses dimana saja dan kapan saja.
Tantangan dalam manajemen perubahan juga dihadapi oleh KemenPAN-RB, salah satunya adalah tantangan untuk mengimplementasi peraturan PerundangUndangan, hal ini berdasarkan wawancara dengan Kepala Bagian Organisasi dan Reformasi Birokrasi Internal (tanggal 5 November 2018) bahwa tantangan eksternal dalam manajemen perubahan di KemenPAN$\mathrm{RB}$ salah satunya yaitu peraturan perundangan yang menjadi masalah besar, terutama bagaimana implementasi peraturan PerundangUndangan. Terkadang banyak peraturan Perundang-Undangan yang tumpang tindih. Tantangan secara internal KemenPAN-RB juga terus melakukan review terhadap peraturan Perundang-Undangan. Secara internal juga terus mengupayakan, salah satu upaya yang dilakukan dengan mengembangkan aplikasi Sistem Informasi Layanan Hukum MenPAN (SiLahkan).

Dalam bidang SDM ASN beberapa capaian penting oleh KemenPAN-RB berdasarkan hasil wawancara dengan Sekretaris KemenPAN-RB (pada tanggal 9 Januari 2019) berdasarkan Road Map Reformasi Birokrasi KementerianPAN-RB Tahun 2015-2019 diantaranya: 1) Penerapan Integrated Human Resources Management System (IHRMS)/SHRM; 2) Penerapan $e$ performance." (Wawancara Mendalam dengan Drs. Dwi Wahyu Atmaji, M.P.A sebagai Sekretaris KemenPAN-RB pada tanggal 9 Januari 2019). Berdasarkan temuan tersebut manajemen perubahan dalam manajemen SDM KemenPAN-RB sudah terjadi perubahan ke arah Strategic Human Resource Management (SHRM), namun dalam kondisi sebenarnya Integrated Human Resources Management System (IHRMS)/SHRM di KemenPAN-RB belum diimplementasikan.

IHRMS sebagai suatu gagasan perubahan kearah perbaikan dalam manajemen SDM KemenPAN-RB belum diimplementasikan karena berbagai kendala internal maupun eksternal, hal ini berdasarkan hasil wawancara dengan Kepala Bagian SDM KemenPAN-RB (30 November 2019), bahwa KemenPAN-RB masih terus berupaya melakukan maping sumber daya sehingga belum mengimplementasikan IHRMS. Selain masalah maping sumber daya, sumber daya pegawai untuk mengoperasikan sistem ini masih membutuhkan bantuan pelatihan oleh 
pihak ke-3. Perubahan Struktur Organisasi dan Tata Kerja (SOTK) juga menyebabkan perubahan standarisasi kompetensi, indikator kinerja utama, nomenklatur struktur organisasi, penyelarasan database, dan penilaian ulang kemampuan organisasi sehingga untuk mengimplementasikan IHRMS masih memerlukan penyempurnaan yang disesuaikan dengan SOTK.

Selain itu permasalahan yang menyebabkan IHRMS belum diimplementasikan adalah kesiapan dari berbagai aspek manajemen SDM dan organisasi. Untuk mendukung terwujudnya SDM KemenPAN-RB yang profesional dan berkinerja tinggi, dibuatlah Roadmap SDM dalam bentuk Human Capital Development Plan (HCDP) KemenPAN-RB yang telah berlaku secara resmi sejak tahun 2013. Roadmap Manajemen SDM KemenPAN-RB adalah rencana mengenai program dan kegiatan yang dirancang untuk mendukung tujuan, namun sampai saat ini belum dilakukan sosialisasi kepada pegawai secara optimal. Selain itu beberapa pekerjaan dalam tahapan masih ada yang belum dilakukan seperti Uraian Pekerjaan atas hasil Analisa Jabatan belum mencantumkan Syarat Jabatan, Peta Jabatan dan Formasi Jabatan. Hal ini menjadi bukti bahwa Manajemen SDM KemenPANRB belum sejalan dengan yang diharapkan yaitu memiliki kompetensi yang sesuai dan profesional sesuai keahliannya. Masih banyak aspek-aspek dalam Manajemen SDM KemenPAN RB yang belum dimiliki untuk mendukung tercapainya harapan KemenPAN$\mathrm{RB}$, hal ini berdasakan temuan dari hasil Audit MSDM KemenPAN-RB sebagai berikut:

Dalam aspek perencanaan SDM, dibutuhkan dukungan dari jajaran pimpinan tertinggi agar berjalan sesuai dengan Roadmap SDM KemenPAN-RB, selain itu belum adanya nomenklatur jabatan untuk SOTK baru menimbulkan kegelisahan dari jajaran pegawai karena merasa pegawai tidak memiliki pekerjaan yang jelas. Kemudian dalam penempatan pegawai masih belum mengacu pada prinsip the right man on the right place, masih cenderung adanya faktor like and dislike masih dirasakan sangat besar. Terbukti dari hasil analisis data kepegawaian, dari 356 pegawai KemenPAN-RB masih terdapat $20 \%$ atau 71 pegawai KemenPAN-RB yang belum sesuai antara kualifikasi jabatan dan jabatannya.

Dalam aspek manajemen kompetensi bahwa standar kompetensi, kamus kompetensi baik soft maupun hard competency masih generik PNS sehingga masih parsial dan belum menggambarkan karakteristik KemenPAN-RB hal ini juga membuat implementasi kompetensi di KemenPAN-RB belum efektif, karena prasyarat yang perlu ada dalam mengimplementasikan MSDM yang sejalan dengan tujuan strategis organisasi adalah adanya Model, Profil beserta Kamus kompetensi yang mencerminkan karakteristik peran dan fungsi setiap jabatan di KemenPANRB sejalan dengan arah strategisnya.

Dalam aspek rekrutmen dan seleksi belum menggambarkan kondisi Manajemen SDM yang dapat memenuhi kebutuhan pegawai KemenPAN-RB sesuai dengan kebutuhan, arah strategis dan karakteristik KemenPANRB karena masih belum ada standar kompetensi sebagai dasar kualifikasi rekrutmen dan belum ada ketentuan metode tes untuk tes kompetensi bidang. Padahal tujuan dari rekrutmen dan seleksi ini bukan hanya usaha organisasi untuk mengisi jabatan atau formasi saja tetapi kandidat yang mengisi formasi tersebut harus dapat dipastikan memiliki kualifikasi dan kompetensi yang tepat sesuai dengan kebutuhan, arah strategis dan karakteristik KemenPAN-RB.

Dalam aspek Sistem Pengembangan SDM kebijakan pengembangan SDM masih mengacu pada pengembangan PNS, KemenPAN-RB belum memiliki dasar untuk pengembangan SDM sesuai kebutuhan pegawai secara individu padahal sistem pengembangan SDM bertujuan untuk menambah pengetahuan, meningkatkan keterampilan dan perubahan sikap sehingga output dari pengembangan SDM diharapkan setiap pegawai dapat mengoptimalkan sumber daya yang dimilikinya dengan optimal untuk mencapai hasil yang diinginkan tentunya sejalan dengan kebutuhan dah arah strategis KemenPANRB. Dalam implementasinya Pengembangan SDM di KemenPAN-RB ini belum memiliki pola diklat khusus yang sesuai dengan karakteristik KemenPAN-RB

Dalam aspek manajemen kinerja yang sudah cukup baik menurut hasil audit manajemen SDM KemenPAN-RB, namun 
dalam impelementasinya masih mengalami berbagai permasalahan. Ketentuan yang mengatur tentang Manajemen Kinerja PNS (ASN) pada dasarnya sudah lengkap, namun belum dapat dilaksanakan sepenuhnya. Hal lain menunjukan keadaan sebaliknya bahwa manajemen kinerja pegawai di KemenPANRB hanya diukur berdasarkan presensi saja. Sasaran Kerja PNS (SKP) telah disosialisasikan dan diujicobakan, namun belum semua unit menyusun (efektif per tahun 2014). Penurunan kinerja organisasi yang dipedomani dari Akuntabilitas Kinerja Instansi Pemerintah menjadi kinerja individu PNS belum secara penuh dipahami sehingga cascading Kinerja organisasi ke individu belum sepenuhnya mencerminkan potret kinerja sesungguhnya.

Aspek manajemen karir sudah tersedia namun masih terdapat sejumlah subsistem dalam manajemen karir yang belum lengkap dan perlu dikembangkan seperti Jalur karir/pola karir secara khusus untuk internal, siklus karir, critical development experience, talent pool, keterkaitan antara pola karir, pola assessment dan pola pengembangan SDM, dan rencana karir individu. Adapun beberapa persoalan yang dihadapi dalam aspek manajemen karir SDM KemenPANRB yaitu belum membuat kriteria perjalanan karir dan persyaratannya untuk setiap jabatan, paling tidak belum transparan dalam hal kompetensi dan prestasi kinerjanya (sistem merit), masih dijumpai persepsi bahwa dalam promosi jabatan dipengaruhi oleh faktor like-dislike, selian itu belum ada keterpaduan antara pola karir dan pola diklat.

Dalam aspek sistem remunerasi sebenarnya sudah cukup lengkap; namun perlu disempurnakan dalam hal Peraturan/Kebijakan, Ketentuan Pemberian Gaji \& Tunjangan sampai dengan Komponennya dan Mekanisme pemberian tunjangan. Implementasi remunerasi belum efektif mengungkit kinerja pegawai, karena penilaian masih pada tataran Organisasi dalam konteks Reformasi Birokrasi, sedangkan Indikator pengukuran kinerja individual pegawai masih terbatas pada kedisiplinan.

Dalam aspek Sistem Informasi Manajemen SDM, kebijakan manajemen informasi sudah ada namun bersifat umum, ketentuan yang bersifat spesifik belum ada. Sistem informasi yang ada sudah dirasakan manfaatnya, tetapi belum optimal mendukung
Bagian SDM sebagai mitra strategik KemenPAN-RB. Aplikasi sistem-sistem yang dikembangkan masih belum sepenuhnya terhubung dan terintegrasi secara fungsi serta perlu adaptasi database yang digunakan dalam aplikasi masih belum sepenuhnya terintegrasi sehingga ada risiko duplikasi data. Informasi database perlu dikembangkan lagi sehingga memenuhi persayaratan data base di UU ASN

Dari pemaparan diatas dapat disimpulkan bahwa Manajemen SDM KemenPAN-RB saat ini masih parsial dalam mengelola SDMnya, sehingga aspek manajemen SDM masih belum terintegrasi satu sama lain yang menyebabkan berbagai permasalahan di setiap aspek. Manajemen SDM yang terintegrasi atau SHRM yaitu suatu konsep manajemen SDM yang menghubungkan strategi organisasi secara keseluruhan dengan sistem Manajemen SDM menjadi sesuatu yang penting untuk memaksimalkan kinerja organisasi dengan meningkatkan inisiatif, kreativitas dan komitmen pegawai untuk sukses (Covey, 2004; Senge, 2006; dalam Caldwell, Truong, Linh, Tuan, 2015).

\section{B. Faktor-Faktor Pengaruh dalam Menerapkan Strategic Human Resource Management}

Adapun gagasan perubahan untuk memiliki sistem manajemen SDM yang terintegrasi melalui gagasan perubahan Sistem Informasi Manajemen SDM Terpadu Berbasis Kompetensi (Si MSDM-TBK) belum dapat diimplementasikan. Sistem yang telah dibangun ini tidak dapat dengan mudah diimplementasikan karena berbagai faktor yang mempengaruhinya. Menurut hasil analisis penulis dari berbagai hasil wawancara tentang faktor-faktor yang mempengaruhi dalam menerapkan manajemen SDM kearah SHRM di KemenPAN-RB adalah faktor Mindset, Organisasional, Kepemimpinan, Knowledge Sharing, Infrastruktur, dan Kompetensi SDM. Untuk itu dibutuhkan suatu model implementasi SHRM di KemenPANRB yang dapat membantu KemenPAN-RB dalam mengimplementaskan sistem tersebut sesuai dengan karakteristik organisasi dan faktor-faktor pengaruhnya. 


\section{Model Implementasi Integrated Human Resource Management System di KemenPAN-RB}

Untuk membuat model implementasi manajemen SDM ke arah SHRM di KemenPAN-RB terlebih dahulu harus dideteksi apa kebutuhan dan akar permasalahan yang dihadapi oleh organisasi. Selain kebutuhan dan akar masalah yang dihadapi dalam manajemen SDM KemenPAN$\mathrm{RB}$, implementasi sistem ini juga terkait dengan rentang waktu dalam memprioritaskan kegiatan yang akan dilakukan, hal ini sejalan dengan hasil wawancara dengan Dosen Ilmu Administrasi dan Pengembangan SDM, FIA, UI Akademisi yang dianggap memiliki kualifikasi dalam hal Strategic Human Resource Management (10 Januari 2017). Berdasarkan hasil temuan di lapangan melalui proses wawancara dengan berbagai stakeholder di KemenPAN-RB maupun dengan praktisi dan akademisi yang dianggap memiliki kapasitas tentang SHRM, maka model implementasi SHRM di KemenPANRB sebagai berikut:

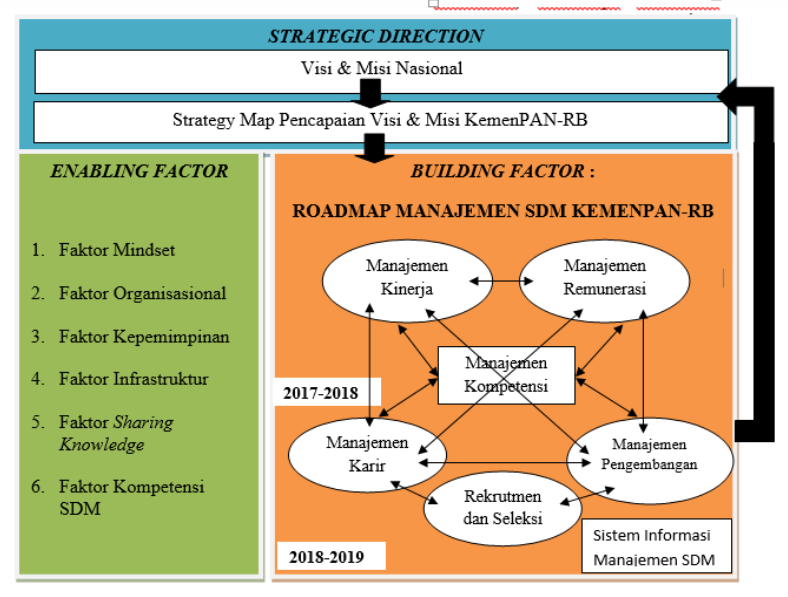

\section{Gambar 4.6 Model Implementasi Integrated Human Resource Management System KemenPAN-RB}

Sumber: Diolah oleh Penulis, 2019

Model Implementasi Strategic Human Resource Management di KemenPAN-RB tersebut berdasarka elaborasi dari teori yang penulis gunakan dan hasil penelitian dokumen maupun penelitian lapangan. Model Human Resource Management System di KemenPAN$\mathrm{RB}$ tersebut diharapkan mampu membantu KemenPAN-RB dalam mengimplementasikan gagasan perubahan dalam manajemen SDM KemenPAN-RB yang sudah dibuat. Model Human Resource Management di KemenPANRB terdiri dari 3 Determinan, diantaranya Determinan Strategic Direction, Determinan Enabling Factor, dan Determinan Building Factor.

Determinan Arah Strategis (Strategic Direction) merupakan aspek yang menjadi dasar dalam menentukan Building Factor. Determinan Strategic Direction terdiri dari Visi dan Misi Nasional dan Strategy Map pencapaian Visi dan Misi KemenPAN-RB. Visi dan Misi Nasional merupakan arah kebijakan nasional yang dibuat oleh Presiden sebagai kepala negara dan kepala pemerintahan. Hal ini sejalan dengan hasil wawancara dengan Kepala Bagian Perencanaan Kinerja dan Penganggaran KemenPAN-RB (5 November 2019) bahwa Bappenas menurunkan program prioritasnya sesuai Nawacitra Presiden dalam bentuk Renstra, nanti K/L mengikuti mana yang menjadi priositas, setiap tahun dibahas lagi antara K/L, Bappenas dan Kementerian Keuangan untuk menentukan Pagu Anggaran. Pernyataan tersebut juga sejalan dengan hasil wawancara Sekretaris KemenPAN-RB (9 Januari 2017) tentang kebijakan strategis KemenPAN-RB sejalan dengan visi dan misi nasional yaitu dengan terlebih dahulu melihat kebijakan nasional mana saja yang dapat didukung oleh KemenPAN-RB mengacunya ke Undang-undang Nomor 17 Tahun 2007 tentang RPJP 2005-2025 dan nawacita pak Jokowi-JK yang secara tegas tertuang dalam Perpres Nomor 2 Tahun 2015 tentang RPJMN 2015-2019. Baik RPJP, RPJMN, dan Nawacita sama-sama menekankan pentingnya pelaksanaan reformasi birokrasi untuk meingkatkan profesionalisme aparatur negara untuk mewujudkan tata pemerintahan yang baik, bersih, efektif, demokratis dan terpercaya. Kemudian dari sana KemenPAN$\mathrm{RB}$ merumuskan Renstra dan program kerja Kementerian PANRB untuk merealisasikan tujuan nasional tersebut, yaitu mewujudkan aparatur negara yang profesional, bersih dan efektif. Jadi, kebijakan strategis Kementerian PANRB sudah pasti sejalan dan sesuai koridor RPJP dan RPJMN.

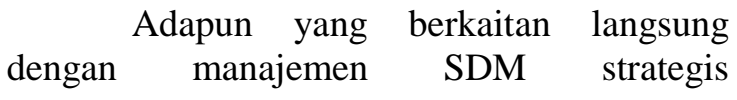


KemenPAN-RB adalah reformasi menajemen SDM yang terintegrasi yaitu dengan digagasnya IHRMS. Untuk itu determinan Building Factor yang sudah dibangun oleh KemenPAN-RB dalam reformasi manajemen SDMnya adalah dengan digagasnya Integrated Human Resource Management System (IHRMS) atau Sistem Informasi Manajemen SDM Terpadu Berbasis Kompetensi ( $\mathrm{Si}$ MSDM-TBK). Latar belakang dibangunnya sistem ini adalah dalam rangka menjalankan misi dan mewujudkan visi serta tujuan strategis tersebut, KemenPANRB telah melakukan berbagai langkah perubahan. Untuk dapat menjalankan sistem ini sesuai dengan tujuan dan ruang lingkup sistem yang telah digagas oleh KemenPAN-RB sesuai dengan rencana pengembangan IHRMS yang sudah dibuat, KemenPAN-RB seharusnya dapat menjalankan manajemen SDM sesuai dengan Pedoman IHRMS yang sudah dibuat. Yang terdiri dari Manajemen Kompetensi, Manajemen Rekrutmen dan Seleksi, Pengembangan SDM, Manajemen Remunerasi, Perencanaan Karir, dan Penilaian Kinerja.

Factor $\begin{array}{rrr}\text { Kemudian } & \text { Debagai } & \text { Determinan } \\ \text { faktor-faktor } & \text { Enabling } \\ \text { yang }\end{array}$ mempengaruhi impementasi IHRSM adalah Faktor Mindset, Faktor Organisasional, Faktor Kepemimpinan, Faktor Sharing Knowledge, Faktor Infrastruktur dan Faktor Kompetensi SDM. Berdasarkan hasil elaborasi teori yang digunakan dan hasil penelitian faktor-faktor tersebutlah yang mempengaruhi implementasi IHRMS dapat berjalan secara efektif.

Faktor Mindset pegawai yang sudah merasa ada di zona nyaman bekerja, faktor mindset terhadap aturan yanag menyebabkan sulit berinovasi dan afktor mindset masyarakat bahwa menjadi PNS dianggap untuk mendapatkan job security menjadi salah satu faktor yang menyebabkan IHRMS di KemenPAN-RB belum diimplemtasikan dengan efektif. Faktor organisasional terutama dalam mengelola perubahan sangat berpengaruh dalam menerapkan reformasi manajemen SDM kearah SHRM di KemenPAN-RB. Karena setiap gagasangagasan perubahan tidak mudah diinternalisasikan maka organisasi harus memiliki manajemen sesuai karakteristik organisasinya untuk dapat mengelola perubahan, sehingga setiap anggota organisasi dapat ikut merasakan kebutuhan untuk berubah.

Pekerjaan pemimpin yang paling utama adalah memastikan perubahan dalam organisasinya untuk merespon tantangan, peluang dan perubahan lingkungan, leadership is about change rather than stability oleh karena itu pemimpin harus membantu pegawai dalam organisasinya melihat kebutuhan untuk berubah dan melakukan cara-cara baru yang lebih baik dalam mengerjakan pekerjaannya. Hal ini menyebabkan faktor kepemimpinan berpengaruh signifikan terhadap penerapan reformasi manajemen SDM kearah SHRM di KemenPAN-RB. Selain itu faktor pengetahuan sangat signifikan, pengetahuan tentang apa tujuan sistem yang digagas, bagaimana cara kerjanya dan siapa yang bertanggungjawab untuk menjalankan sistem tersebut sangat dibutuhkan. untuk itu knowledge sharing merupakan faktor yang penting dalam menerapkan perubahan manajemen SDM KemenPAN-RB. Faktor lain yang juga berpengaruh signifikan dalam mengimplementasian reformasi manajemen SDM ke arah SHRM adalah adanya infrastruktur yang memadai, karena sistem ini menggunakan IT base, maka infrastruktur IT yang mendukung sistem ini juga harus dapat mendukung. Faktor yang menggerakan strategi organisasi itu pun penting, sehingga organisasi harus memiliki SDM yang kompeten, bahwa kapabilitas SDM untuk mengeksekusi itu juga penting.

Berdasarkan hasil elaborasi teori yang digunakan dan hasil penelitian faktor-faktor tersebutlah yang mempengaruhi implementasi IHRMS dapat berjalan secara efektif. Dengan model implementasi IHRMS tersebut diharapkan dapat membantu KemenPANRB untuk menerapkan gagasan perubahan yang sudah dibangun. Dengan begitu visi, misi dan strategi KemenPAN-RB untuk menjadikan aparatur negara yang bersih, kompeten dan melayani dapat tercapai dimulai dari internal lembaganya sehingga dapat menjadi role model bagi Kementerian/Lembaga/Pemerintah daerah lainnya. Apabila implementasi IHRMS dapat berhasil tentunya disesuaikan dengan karakteristik organisasinya maka akan mendukung terwujudnya tata pemerintahan yang baik dengan birokrasi pemerintahan yang profesional, berintegritas tinggi, menjadi pelayan masyarakat dan abdi negara sesuai 
Grand Design Reformasi Birokrasi di Indonesia dengan begitu visi misi nasional pun tercapai.

\section{Simpulan}

Salah satu reformasi dalam bidang SDM di KemenPAN-RB adalah adanya gagasan manajemen SDM kearah Strategic Human Resource Management (SHRM) melalui Integrated Human Resource Management System (IHRMS). Namun pada kenyataannya manajemen SDM di KemenPAN-RB ini belum mengimplementasikan Strategic Human Resource Management (SHRM) atau dapat dikatakan masih parsial. Hal ini disebabkan oleh Faktor-faktor yang mempengaruhi dalam Reformasi Manajemen SDM kearah SHRM di KemenPAN-RB menurut hasil analisis penulis dari berbagai hasil wawancara adalah faktor Mindset, Faktor Organisasional, Faktor Kepemimpinan, Faktor Sharing Knowledge, Faktor Infrastruktur, dan Faktor Kompetensi SDM. Untuk dapat mengimplementasikan dengan efektif gagasaran perubahan kearah SHRM melalui IHRMS dalam mengelola SDM di KemenPAN-RB dibutuhkan suatu strategi dan aksi yang digambarkan melalui model implementasi yang dapat membantu KemenPAN-RB mulai mengimplementasikan sistem tersebut sesuai dengan karakteristik organisasi dan faktor-faktor pengaruhnya. KemenPAN-RB terlebih dahulu harus mendeteksi apa kebutuhan dan akar permasalahan yang dihadapi oleh organisasi dan rentang waktu dalam memprioritaskan kegiatan yang akan dilakukan.

\section{Saran}

KemenPAN-RB harus mampu membuat dan melakukan agenda-agenda manajemen perubahan (Change Management Agenda) yang tepat mulai dari mitigasi dan rencana aksinya (Planning Action) secara konkret disesuaikan dengan visi dan misi organisasinya. Termasuk salah satunya untuk merubah Pola Pikir (Mindset) sebagai faktor penting apabila ingin mengimplementasikan SHRM dengan efektif, selain peran pimpinan yang memiliki komitmen kuat, sumber daya manusia yang memiliki kapasitas sesuai kualifikasi pekerjaannya dan infrastruktur dalam melakukan pekerjaan yang memadai. Seharusnya KemenPAN-RB mampu membuat dan mengimplementasikan sistem yang mengharuskan pegawai melakukan apa yang diharapkan oleh organisasi dengan menggunakan Teknologi Informasi. KemenPAN-RB melalui Bagian SDM yang memiliki tanggungjawab dalam setiap perubahan manajemen SDM di KemenPANRB seharusnya dapat membangun pola bagaimana pegawai KemenPAN-RB seluruhnya paham mengenai perubahan manajemen SDM ini. Model Implementasi SHRM di KemenPAN-RB berdasarkan hasil penelitian ini diharapkan juga dapat menjadi bahan masukan bagi KemenPAN-RB terkait aspek-aspek utama yang berperan penting untuk membantu organisasi dalam mencapai visi dan misinya melalui paradigma Strategic Human Resource Management.

\section{Daftar Pusataka}

Aruan, Cyti Daniela. 2016. Human Resource Management Reform in The Indonesian Civil Service: Towards Strategic Fit?. Faculty of Business Government and Law: University of Canberra

Becker, B.E., \& Huselid, M.A. 1998. High Performance Work Systems and Firm Performance: A Synthesis of Research and Managerial Implications. Research in Personnel and Human Resources Management

Caldwell, C., Truong, D.X., Linh, P.T. and Tuan, A. 2015. Strategic Human Resource Management as Ethical Stewardship. Journal of Business Ethics, Vol. 98

Creswell, John W. 2010. Research Design : Pendekatan Kualitatif, Kuantitatif dan Mixed, Yogyakarta : Pustaka Pelajar

Dessler, Gary. 2015. Manajemen Sumber Daya Manusia. Jakarta: Penerbit Salemba Empat.

Flynn, F, J. 2006. How much is it worth to you? Subjective Evaluation of Help in 
Organizaton. Research in Organization Behaviour. Vol.95

Huselid, M.A., Jackson, S.E., \& Schuler, R.S. 1997. Technical and strategic human resources management effectiveness as determinants of firm performance, Academy of Management Journal

Ivancevich, John M dan Konopaske, Robert. 2012. Human Resource Management. New York: McGraw-Hill Irwin

Lewin, Kurt. 1951. Field Theory in Social Science. New York: Harper \& Row

Manchester Open Learning (MOL), 1993. Planning and Managing Change. London: Kogan Page Ltd

Manning, Karen. 2010. Strategic Human Resource Management and The Australian Public Sector. Transylvanian Review of Administrative Sciences

Manning, Karen. 2010. Strategic Human Resource Management and The Australian Public Sector. Transylvanian Review of Administrative Sciences

Mello, Jeffrey A. 2015. Strategic Human Resource Management, Australia : South-Western/Cengage Learning

Moleong, Lexy J. 2010. Metode Penelitian Kualitatif. Bandung: Rosda Karya.

Mondy, R Wayne. 2008. Human Resource Management. Pearson Education

Pynes, Joan E. 2009. Human Resources Management for Public and Nonprofit Organization Third Edition. New Jersey: Wiley

Robbins, Stephen P. 1991. Organizational Behavior. Englewood Cliffs: Prentice Hall

Spector, Bert. 2013. Implementing Organizational Change. New Jersey: Pearson Education,Inc
Tompkins, J. 2002. Strategic human resources management in government: Unresolved issues. Public Personnel Management. 